\title{
Interdisciplinary Approach of Amelogenesis Imperfecta: 10 Years of Clinical Follow-Up
}

\section{Abordagem Interdisciplinar da Amelogênese Imperfeita: 10 Anos de Acompanhamento Clínico}

\author{
Mauro Toma ${ }^{\mathrm{a}}$; Jessica Rico Bocato ${ }^{\mathrm{b}}$; Carlos Magno Goshe ${ }^{\mathrm{a}}$; Thais Teixeira Borsato $;$;na Claúdia de Castro Ferreira \\ Conti ${ }^{\mathrm{b}}$; Thais Maria Freire Fernandes ${ }^{\mathrm{b}}$; Paula Vanessa Pedron Oltramari*b
}

aprivate Practice

bUnopar, Stricto Sensu Graduate Program in Dentistry. PR, Brazil.

*E-mail: pvoltramari@hotmail.com

Recebido em: 14/09/2020

Aprovado em: 15/12/2020

\begin{abstract}
Amelogenesis imperfecta (AI) is an inherited disease that expresses a disorder in the development of enamel structure. In its mildest form, it promotes tooth color change; and in more severe cases, it presents a loss of enamel structure initiated during the eruption phase. Different AI manifestations can coexist in the same patient or in the same tooth, both in the primary and permanent dentures. In addition, several subtypes are described, characterized according to the variety of phenotype and genotype. Successful treatment requires early diagnosis and therapeutic solutions involving different dental specialties. Although some professionals prefer to postpone permanent rehabilitation until the development of complete permanent dentures, the aesthetic and functional impact of this disease in childhood and adolescence requires that restorative treatment be started as soon as possible. The proposed therapies demonstrate numerous challenges such as extreme dentinal sensitivity, difficulties installing and maintaining the orthodontic appliance and the need for restorative and prosthetic intervention in malformed teeth. This work aims to demonstrate the interaction between Orthodontics, Restorative Dentistry and Prosthesis in the treatment of a patient with AI, reporting the success of treatment involving aesthetics, function and well-being and the long-term benefit of this interdisciplinary approach for patients with this disease.
\end{abstract}

Keywords: Orthodontics. Amelogenesis Imperfecta. Mouth Rehabilitation.

\section{Resumo}

A amelogênese imperfeita (AI) é uma doença hereditária que expressa uma desordem no desenvolvimento da estrutura do esmalte. Na sua forma mais branda, promove alteração na cor dos dentes; e em casos mais severos, apresenta perda de estrutura do esmalte iniciada durante a fase de irrupção. Diferentes manifestações da AI podem coexistir no mesmo paciente ou no mesmo dente, tanto na dentadura decídua quanto na permanente. Além disso, são descritos diversos subtipos, caracterizados de acordo com a variedade do fenótipo e genótipo. O sucesso do tratamento requer diagnóstico precoce e soluções terapêuticas que envolvam diversas especialidades odontológicas. Embora alguns profissionais prefiram adiar a reabilitação definitiva até o desenvolvimento da dentadura permanente completa, o impacto estético e funcional desta doença na infância e adolescência exige que o tratamento restaurador seja iniciado o mais cedo possivel. As terapias propostas demonstram inúmeros desafios como a sensibilidade dentinária extrema, as dificuldades para instalação e manutenção do aparelho ortodôntico e a necessidade de intervenção restauradora e protética em dentes com má formação. O presente trabalho tem como finalidade demonstrar a interação entre a Ortodontia, a Dentística Restauradora e a Prótese no tratamento de um paciente com AI, relatando o sucesso do tratamento envolvendo estética, função, bem estar e o beneficio em longo prazo desta abordagem interdisciplinar para os portadores desta doença.

Palavras-chave: Ortodontia. Amelogênese Imperfeita. Reabilitação Bucal.

\section{Introduction}

Amelogenesis imperfecta (AI) is an inherited disease that expresses a disorder in the development of enamel structure. In its mildest form, it promotes tooth color change; and in more severe cases, it presents a loss of enamel structure. The estimated frequency of $\mathrm{AI}$ in the population ranges from 1: 718 and 1: 14.000 and may be present in both dentitions, deciduous and/or permanent ${ }^{1-3}$. In addition, several subtypes are described, characterized according to the wide variety of phenotype and genotype ${ }^{4,5}$.

According to Witkop classification dated from $1988^{5}$, AI may have different characteristics. Thus, hypoplastic AI is characterized by deficiency in the enamel matrix production; hypocalcified, expresses inadequate calcification and enamel can have a soft consistency, affecting the dental anatomy. Whereas the hypo maturated one, shows a difficult enamel maturation, showing discoloration spots ${ }^{4,5}$. Due to these properties, the main clinical AI problems ARE sensitivity, loss of vertical dimension, dental malocclusion and aesthetics ${ }^{6}$.

Planning is related to an interdisciplinary approach and several factors such as socioeconomic status and the disorder severity determine the type of treatment ${ }^{6}$. Due to the psychological impact and the negative influence on self-esteem of affected patients, treatment is extremely necessary as early as possible ${ }^{6,7}$. However, for many years, due to the difficulty of diagnosis and the limitations of the rehabilitating materials, 
the treatment was conducted with multiple extractions and complete denture prostheses ${ }^{6-8}$

Currently, advances in adhesive materials and greater scientific knowledge allow for early diagnosis and longerlasting treatment ${ }^{8,9}$. Therefore, it is recommended that even before the choice of materials and therapies, the treatment plan should be elaborated and divided into phases: prevention, rehabilitation and follow-up ${ }^{8-11}$.

The objective of this study is to present a report of a clinical case of AI, where the patient complaint involved extreme dental sensitivity and low self-esteem due to dental aesthetics. After 10 years of follow-up, it was possible to perceive the success of the multidisciplinary treatment involving Orthodontics, Dentistry and Prosthesis.

\section{Case Report}

\subsection{Diagnosis and Etiology}

A 16-year-old female patient was referred to a private clinic due to the diagnosis of AI. Her main complaint in addition to the aesthetic characteristic was the great dental sensitivity that prevented her from performing adequate hygiene and hindered her chewing. Thus, for several years she received preventive and restorative treatment in both deciduous and permanent dentitions.

The clinical examination revealed a convex facial profile, lack of lip sealing, deviation of the upper mean line of $3 \mathrm{~mm}$ to the left, slight asymmetry in the frontal view, unilateral right chewing, vertical facial pattern (dolichofacial) (Figure 1).

Figure 1 - Extraoral initial photographs (1- front view and 2-profile)

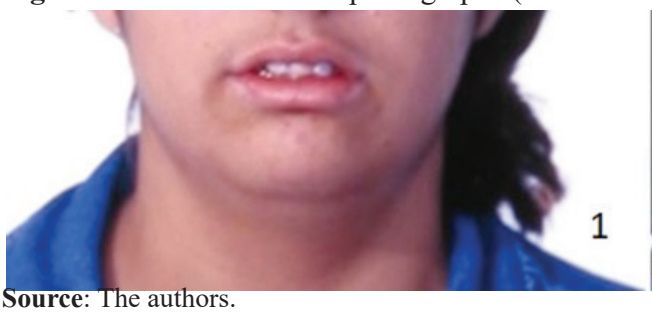

Dentally, the color of the teeth varied from yellow to dark yellow, dark brown spots, clinical small crowns of the posterior teeth, malocclusion with class 11 molar ratio, mild anterior superior and inferior crowding, right superior canine in infra-occlusion, double dentoalveolar protrusion, overjet and discreet open bite. In addition, she presented caries caused by hypoplasia, multiple restorations with composite resin, temporary acrylic resin in the canine teeth and second upper right molar (13 and 17) (Figure 2).

Figure 2 - Extraoral initial photographs (1- front view, 2-left side and 3 right side)
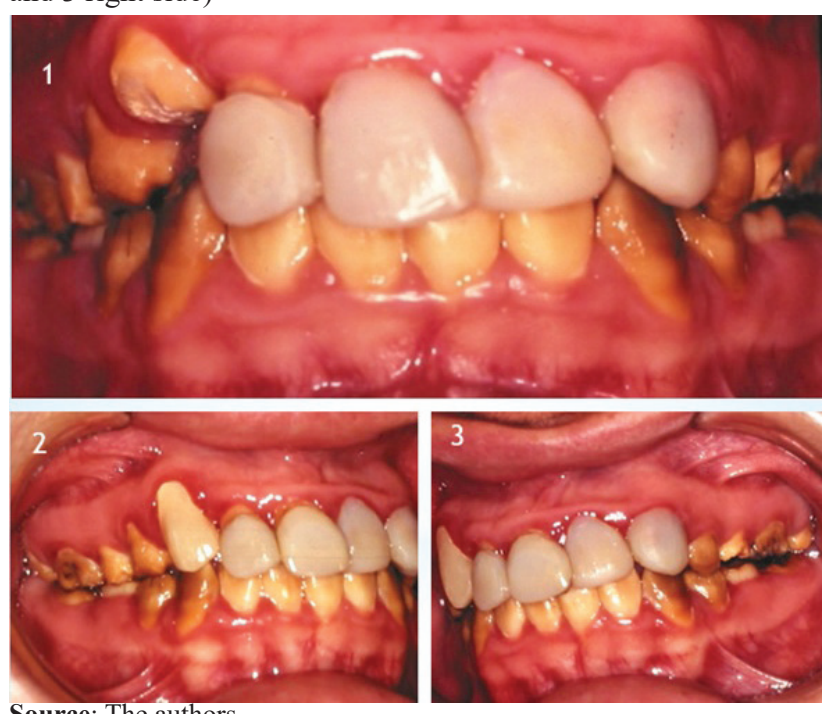

Source: The authors

The complementary examination confirmed the midline deviation and severe teeth erosion and abrasion, mainly the

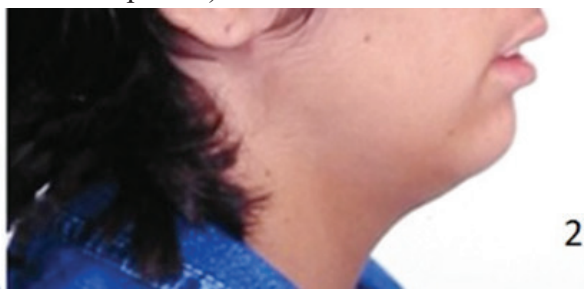

molars due to enamel hypoplasia. The panoramic radiograph was determinant to observe the agenesis of the lower second pre-molars, of the left upper lateral incisor and of the upper and lower right and left molars ( Figure 3).

Figure 3 - Initial panoramic

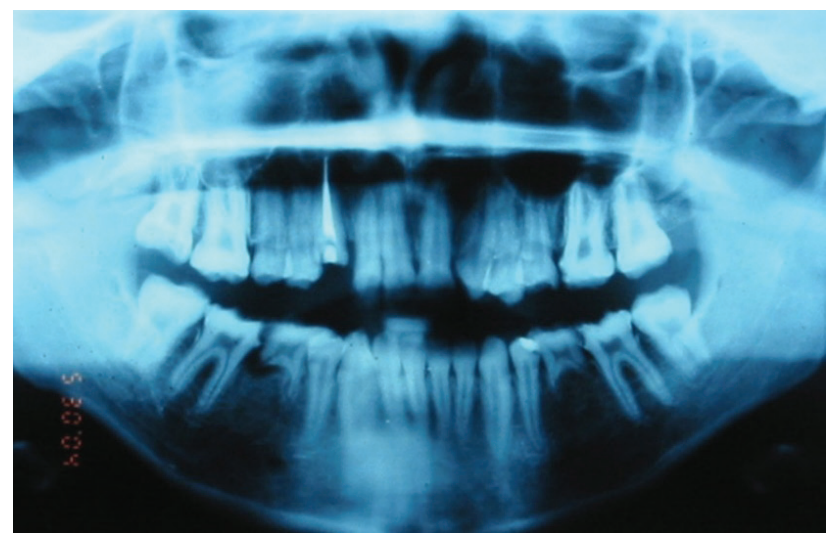

Source: The authors.

\subsection{Treatment objectives}

The objective was to integrate orthodontic, periodontal, endodontic and prosthetic treatment in order to re-establish a harmonic smile, eliminate dental hyper sensibility and improve the chewing function.

The special orthodontic objectives included the retrusion of the upper anterior teeth, midline correction, by the extraction of the first upper right premolar. In the mandible (lower arch, in the mandibular arch), it was opted for the extraction of the deciduous teeth and the space closing, with anchorage loss. 


\subsection{Treatment alternatives}

Some alternatives have been presented for the patient and their guardians, such as: rehabilitating treatment without involving orthodontic treatment. A rehabilitating treatment without involving orthodontics could have been carried out, but there would be difficulty replacing elements 75 and 85 , due to the agenesis of teeth 35 and 45 . This would involve the need for single-tooth denture with implants or 3-element fixed denture, even if these prostheses were made later, due to the patient's age, the discrepancy of the size of the second deciduous molar for a second premolar could be relevant.

\subsection{Treatment progress}

Prior to treatment the patient and her parents were informed of all the procedures to be performed and signed a consent form.

Serial restorations were performed on multiple teeth in the upper and lower arcades due mainly to the presence of caries. In the posterior teeth with short crowns, restorative retreatments were performed in order to recover the vertical dimension and provide a better adaptation of the orthodontic bands (Figure 4). Whereas in the lower teeth, the restorations created an orthodontic aesthetic improvement, however, due to the large amount of crowding, a smile harmony would only be achieved at the end of the treatment (Figure 5).

Figure 4 - 1-Absolute isolation performed to restore teeth with presence of cavities. 2- Restorative retreatments in upper teeth with short crowns. 3- Intraoral photography after restorative treatment
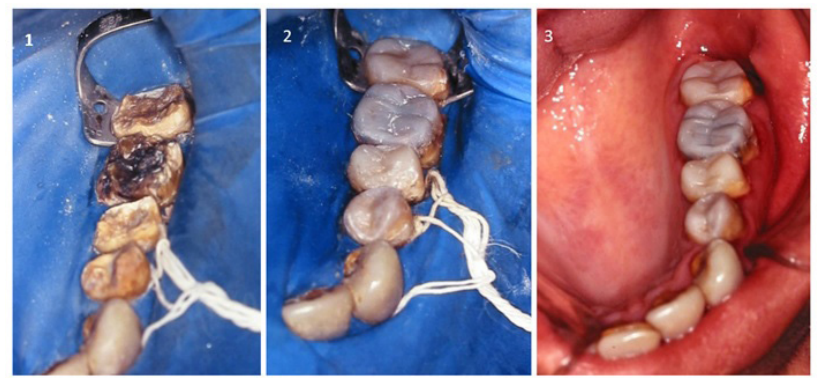

Source: The authors

Figure 5 - Restorations in lower teeth to create an improvement in orthodontic pre-treatment aesthetics

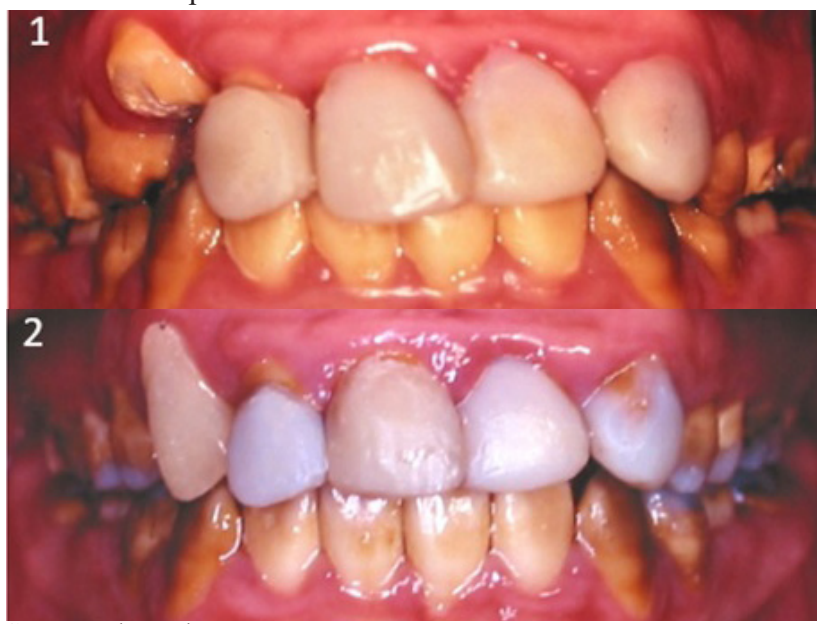

Source: The authors.
After preventive and restorative procedures, extractions of the deciduous teeth 75 and 85 were performed, and permanent 14 for midline adjustment, due to agenesis of tooth 22. Then, bands were installed in the upper and lower posterior molars, and in the lower teeth, bonding with edgewise brackets was performed ( Kirrium Abzil- 3M OralCare).

Then, with the complete appliance installed, the alignment and leveling of the dental arches was carried out, from a progressive evolution of the wires. Upper teeth retraction with the midline correction to the right was performed. In the lower arch, anchorage loss was done to improve the antero-posterior relationship.

The space closing mechanism was performed with bull handles on steel wires with a 0.017 "x 0.025 " gauge and successively finishing with elastic bands for class II welded on the arch. The treatment ended with an excellent occlusion, however, on the left side, due to agenesis of tooth 22 , the premolar 24 replaces the canine 23 (Figure 6).

Figure 6 - Complete appliance installed and spaces closure mechanics, 1- retraction of the right upper canine, 2- on the left side, due to agenesis of tooth 22 , the premolar 24 replaces the canine 23

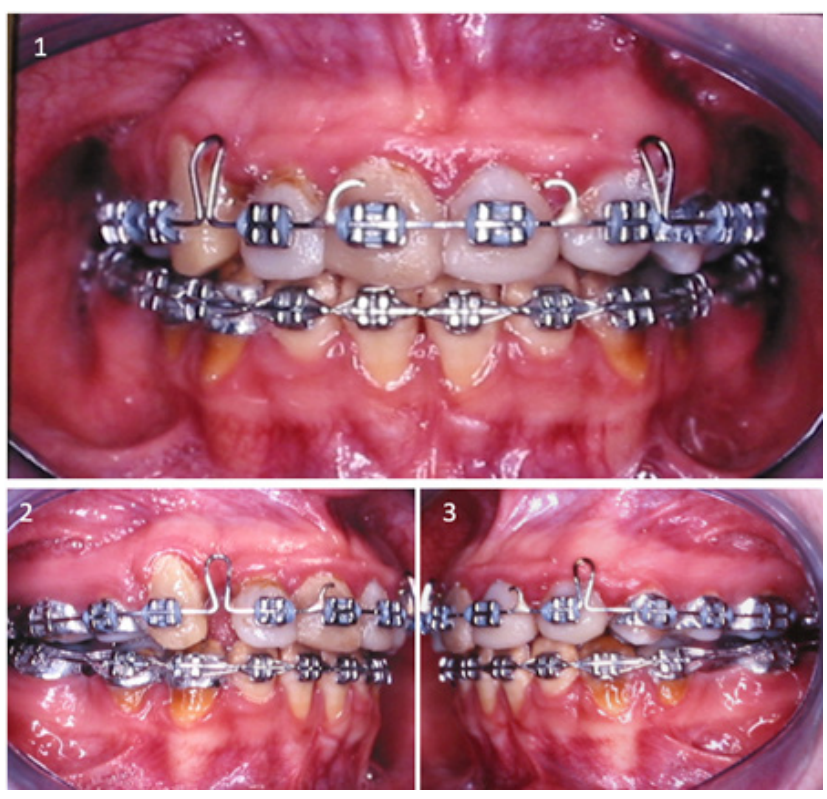

Source: The authors.

After finishing and removing the orthodontic appliance (Figure 7), endodontic treatment was performed in all teeth due to extreme pain the patient felt caused by hypersensitivity and can be visualized through the final panoramic (Figure 8). Multidisciplinary treatment continued to follow with diagnostic waxing for prosthetic rehabilitation planning (Figure 9). In this phase, the patient can imagine how her smile would look and can participate in the choice of size and shape of the teeth. 
Figure 7 - Result after removal of the orthodontic appliance

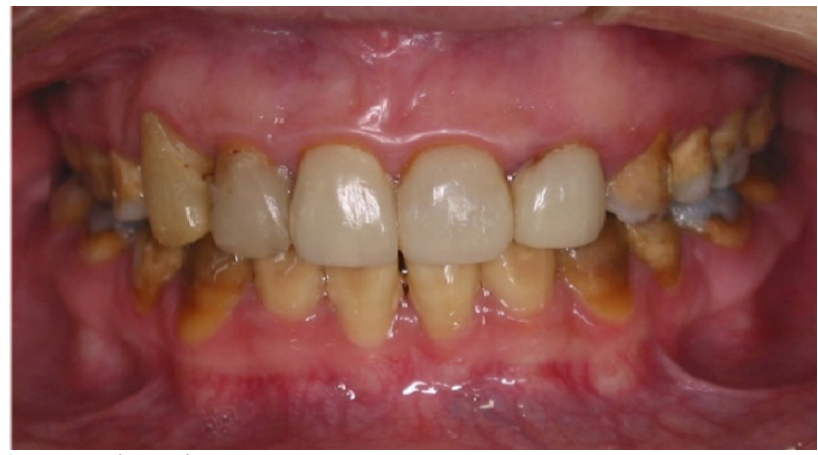

Source: The authors.

Figure 8 - Panoramic after endodontic treatment

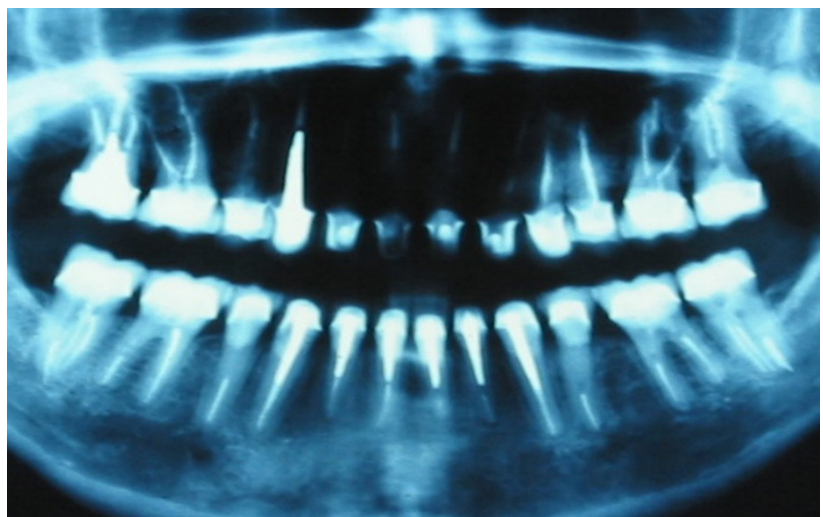

Source: The authors.

Figure 9 - Result after diagnostic waxing (1- front view, 2- left side and 3-right side)
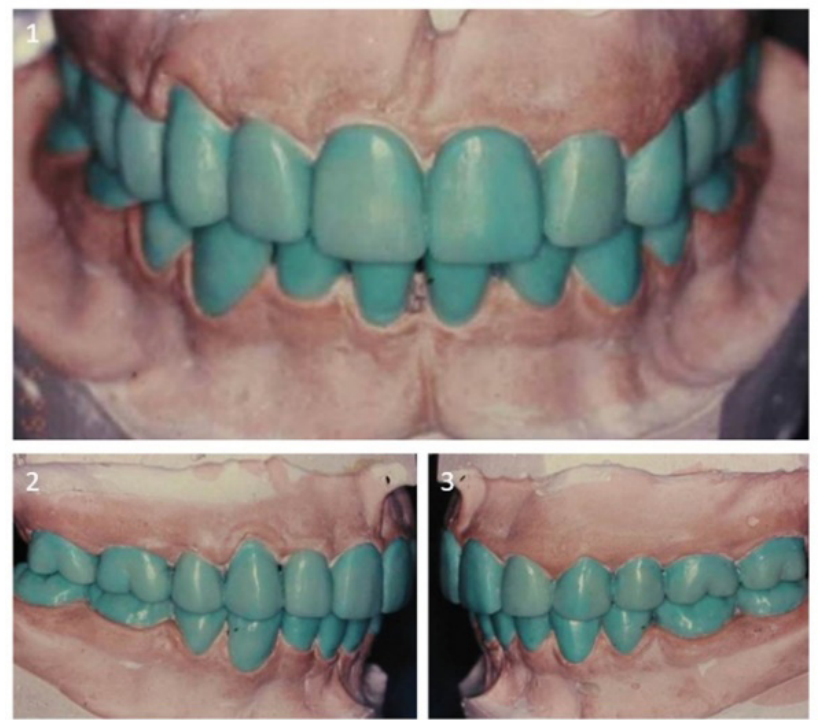

Source: The authors.

The next step was to perform the preparation of the temporary crowns in acrylic resin and later provisional cementation (Figure 10). Meanwhile, prosthetic preparations were performed in all teeth to make the nucleus and permanent porcelain crowns (Figure 11). This step already corresponded to one of the final procedures and the gradual improvement in the patient's aesthetics and quality of life was already visible throughout the treatment (Figures 12 and 13).
Figure 10 - Result after temporary crowns cementation in acrylic resin (1- front view, 2- left side and 3-right side)

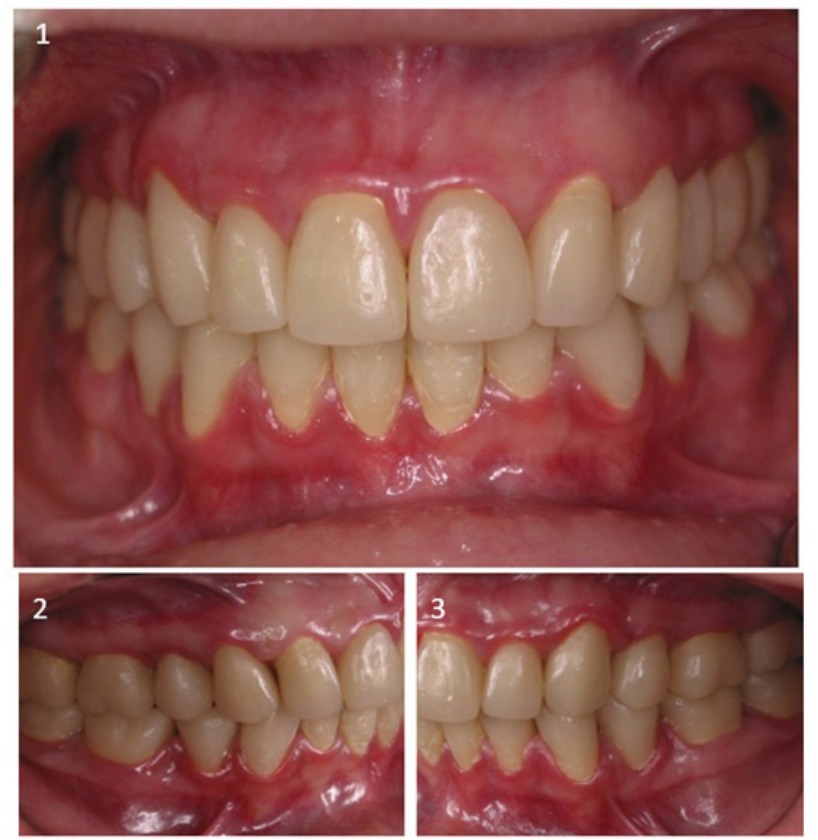

Source: The authors.

Figure 11 - Result after definite crowns cementation in porcelain (1- front view, 2- left side and 3-right side)

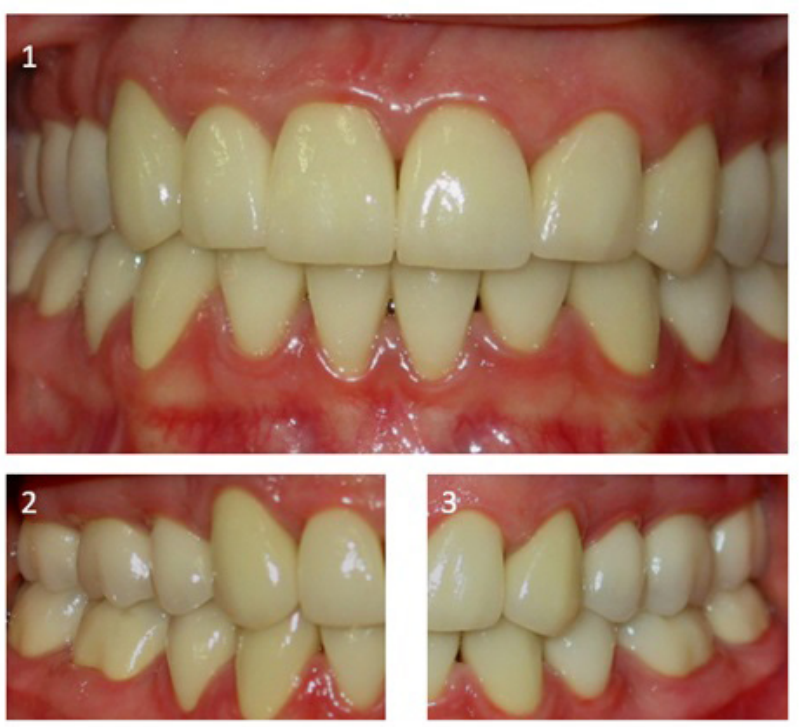

Source: The authors.

Figure 12 - Intraoral photos showing the evolution of the case. (1-initial, 2-dentistry, 3-orthodontic, 4- removal of appliance, 5temporary and 6-final)
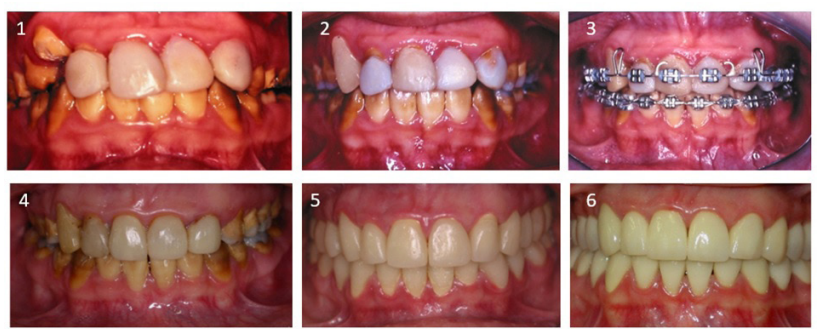

Source: The authors. 
Figure 13 - Extraoral photographs showing the evolution of the case (1- initial, 2- after removal of the appliance and 3- final)

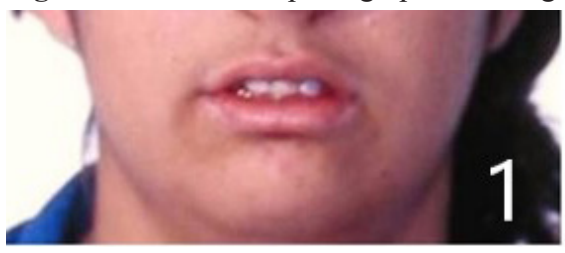

Source: The authors.

\subsection{Treatment results}

The treatment objectives were achieved and the smile established harmony. There was a considerable improvement in facial function and aesthetic, as well as corrections of dental inclinations, dental relationship in occlusion key, adequate overjet and overbite, coincident midlines and no remaining spaces.

Post-treatment photographs showed good intercuspation, lower space closure, correction of the lower molar torque with visible improvement in the clinical crowns height, a good symmetry of the dental arches.

After the completed orthodontic treatment, all upper and lower teeth received ceramic crowns. This interdisciplinary approach improved the patient's facial, dental and self-esteem aspects.

After 10 years after the end of treatment, the patient returned for evaluation and could realize that in the long term there were numerous benefits with this approach. Among these benefits pain improvement, favorable esthetics, periodontal health and occlusal stability after treatment are included (Figures 14 and 15).

Figure 14 - Extra-oral photographs after 10 years of follow-up

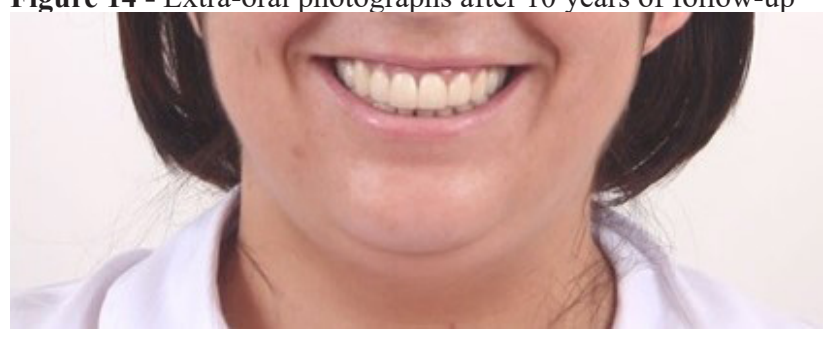

Source: The authors.

Figure 15 - Extra-oral photographs after 10 years of follow-up

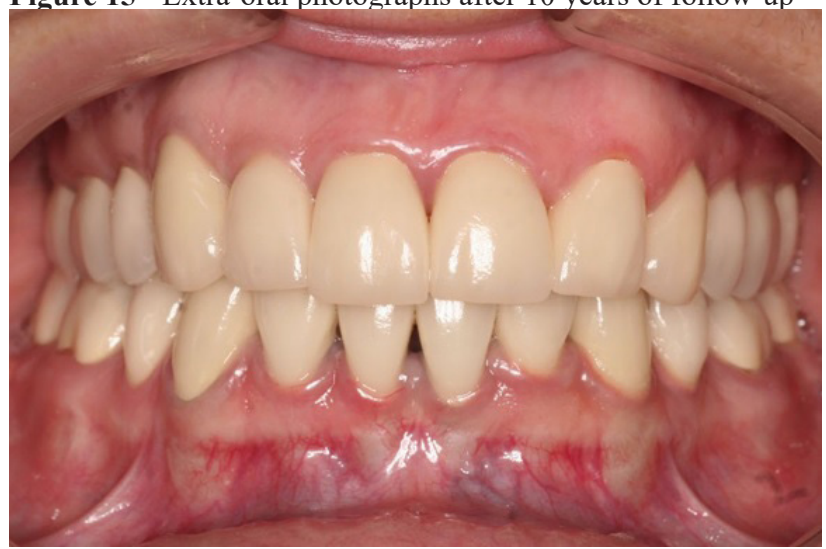

Source: The authors.

\subsection{Discussion}

Amelogenesis imperfecta is a genetic alteration affecting the dental enamel morphology, which may occur in deciduous and/or permanent dentition. Its classification is comprehensive and is characterized in various types, based on heredity, histopathology and specific dental characteristics. Witkop ${ }^{4,5}$ distinguishes 4 types of AI based on phenotype, however, they can be subdivided into 15 categories when based on heredity.

Heredity was proposed as the main factor, leading to a new classification proposed by Neville: A) Imperfecta Hypoplastic; b) Imperfecta Hypocalcified, with its variants of hypo maturation and hypocalcification; and c) Amelogenesis Imperfecta with Taurodontism (hypo mature/hypoplastic AI). This new classification is proposed to move forward in a new classification system, based on inheritance mode, with secondary discriminators that include phenotype, molecular bases and biochemical results, which in the future will be directly applicable in patients' treatment ${ }^{12}$.

Because it presents a broad clinical spectrum, early diagnosis for correct dental planning is of paramount importance $^{13,14}$. Therefore, the treatment should be composed of phases: A) preventive; b) restorative; and, c) maintenance. Nevertheless, the professional should be attentive to the criteria such as age, type of AI, socioeconomic conditions, oral health, and time-of-treatment expectation.

The main objectives of the treatment plan should include pain control, prevention, stabilization, restoration and maintenance of aesthetics and function. The treatment begins with deciduous denture and continues to permanent as teeth erupt $^{14}$. However, the procedures vary according to patients' needs and planning may change according to the clinical characteristics and severity of dental injuries ${ }^{13,14}$.

When long-term stability is in question, the risks and benefits of the treatment plan should be carefully evaluated to achieve the best possible results, according to the specific needs of each patient ${ }^{14}$. In a recent study ${ }^{15}$ with the purpose of exploring experiences and the impact on daily life of families with children with AI, parents reported nuisance due to the lack of permanent and lasting treatment.

According to Ghanei et al. ${ }^{16}$ patients with AI often face circumstances that require emergency care due to tooth fractures and restorations, pain and discomfort. In addition, the longevity of dental restorations in children with AI is significantly lower compared to people who do not have it.

In fact, these enamel changes can cause several problems 
for the individual, including: excessive sensitivity to thermal changes, dental wear (often up to gingival level), loss of vertical dimension, anterior open bite and posterior cross bite.

The present case report describes the interdisciplinary treatment of an AI-bearing patient, who presented a malocclusion of skeletal class $11,1^{\text {st }}$ division, with an overjet of approximately $4 \mathrm{~mm}$ and an open bite. In addition to the orthodontic question, an important complaint of the patient was due to the pain caused by the dental hypersensitivity. Thus, a multidisciplinary approach was proposed with the objective of reestablishing the aesthetics and functional capacity, recovering the patient's self-esteem and quality of life.

One of the orthodontic problems observed in the patient was the presence of anterior open bite. As presented in some studies ${ }^{17-19}$, they showed that the prevalence of Open Bite in individuals affected by AI is much higher than in the general population. Thus, it is suggested that the etiology of malocclusions in individuals with AI may be due to genetic and non-local factors ${ }^{20}$.

Regarding the patient's treatment, it involved extensive and complex procedures, such as endodontic treatment in all teeth before permanent porcelain crowns were installed. This is due to the fact that AI decreases enamel thickness and causes dentin exposure, another reason is that during the prosthetic preparation procedure, due to dental enamel porosity, there is a great chance of pulp exposure. In addition, the patient presented multiple tooth caries and with considerable loss of dental structure ${ }^{21}$.

In permanent dentition, different treatments, from temporary restorations to definitive prosthetic rehabilitation, have been reported in the literature ${ }^{13-15}$. Therefore, treatment may vary from no intervention (mild cases), total or partial restoration (moderate) and even prostheses and implants (severe cases) ${ }^{14}$. In this case, the porcelain crown procedure was chosen for all teeth due to long-lasting results and minimal adverse effects ${ }^{15}$.

AI treatment is important for the patient's oral functionality, psychosocial and aesthetics health. Although it is a low prevalence condition, affected patients suffer from numerous clinical problems affecting quality of life. Partially or in the total absence of dental enamel, it is also associated with pain caused by final thermal chemical stimuli. Reduced crown caused by incomplete eruption causes chewing function and occlusal vertical dimension problems ${ }^{13-15}$.

This case report, in addition to presenting a complex treatment involving several specialties, showed the resolution of the case in a satisfactory way and stability after 10 years of follow-up. This result shows that there was a well-employed treatment plan and success with the multidisciplinary approach.

Still, a 10-year follow-up study of adult patients with AI found aesthetic problems both in the procedures performed with composite resins and in the cases that used porcelain.
Regarding the resin, it is due to a biofilm creation around the tooth causing long-term infiltrations. The main reason for the porcelain crown replacement is due to the fact that the margins of the crowns are similar to the teeth color, and thus, the aesthetic result of the pure ceramic pure or crowns are more favorable when compared to the metallo-ceramics ones $^{23}$.

\section{Conclusion}

AI is a serious anomaly that results in lower quality of life related to oral health and can cause some physiological problems. Patients need extensive treatment and planning should be mainly according to age, socioeconomic conditions, type and severity of the disorder. Due to the potential psychological impact of this disease in childhood and adolescence, it requires that aesthetic treatment be initiated as soon as possible. With early diagnosis, therapeutic decisions and more chance of treatment success are better, guaranteeing a prognosis and stability of the case.

\section{References}

1. Crawford PJ, Aldred M, Bloch-Zupan A. Amelogenesis imperfecta. Orphanet J Rare Dis 2007;2:17. doi:10.1186/17501172-2-17.

2. Chanmougananda SC, Ashokan KA, Ashokan SC, Bojan $\mathrm{AB}$, Ganesh RM. Literature review of amelogenesis imperfecta with case report. J Indian Acad Oral Medic Radiol 2012;24(1):83-7.

3. Bäckman B, Holm AK. Amelogenesis imperfecta: prevalence and incidence in a northern Swedish county. Community Dent Oral Epidemiol 1986;14(1):43-47. doi:10.1111/j.1600-0528. 1986.tb01493. x.

4. Witkop CJ, Sauk JJ. Heritable defects of enamel. In: Stewart R, Prescott CV. Oral facial genetics. St. Louis: Mosby Company; 1976. p.151-226.

5. Witkop, C.J. Jr. Amelogenesis imperfecta, dentinogenesis imperfecta and dentin dysplasia revisited: problems in classification. J Oral Pathol 1988;17:547-53.

6. CangerEM,CelenkP,Yenísey M,OdyakmazSZ.Amelogenesis imperfecta, hypoplastic type associated with some dental abnormalities: a case report. Braz Dent J 2010;21(2):170-174. doi:10.1590/s0103-64402010000200014.

7. Varela M, García-Camba JE. Impact of orthodontics on the psychologic profile of adult patients: a prospective study. Am J Orthod Dentofacial Orthop 1995;108(2):142-8. doi: 10.1016/ s0889-5406(95)70076-5.

8. Chen $\mathrm{CF}, \mathrm{Hu}$ JC, Bresciani E, Peters MC, Estrella MR. Treatment considerations for patient with Amelogenesis Imperfecta: a review. Braz Dent Sci 2013;16(4):7-18. doi: 10.14295/bds.2013.v16i4.904

9. Ardu S, Duc O, Krejci I, Perroud R. Amelogenesis imperfecta: a conservative and progressive adhesive treatment concept. Oper Dent 2014;39(3):336.

10. Patil PG, Patil SP. Amelogenesis imperfecta with multiple impacted teeth and skeletal class III malocclusion: complete mouth rehabilitation of a young adult. J Prosthet Dent 2014;111(1):11-5. doi: 10.1016/j.prosdent.2013.06.010.

11. Kamble VD, Parkhedkar RD. Multidisciplinary approach 
for restoring function and esthetics in a patient with amelogenesis imperfecta: a clinical report. J Clin Diagn Res 2013;7(12):3083-3085. doi: 10.7860/JCDR/2013/6665.3860.

12. López Jordi MC, Szwarc E. Diagnóstico y tratamiento integral en pacientes con amelogénesis imperfecta. Reporte de un caso. Rev Odontopediatr Latinoam 2019;9(1).

13. Borde BT, Araújo IRS, Valente AGL, Tannure PN. Desafios no diagnóstico e tratamento da amelogênese imperfeita: relato de caso. Rev Odontol Univ Cid São Paulo 2018;30(2) 216-22.

14. Apaydin A, Sermet B, Ureturk S, Kundakcioglu A. Correction of malocclusion and oral rehabilitation in a case of amelogenesis imperfecta by insertion of dental implants followed by Le Fort I distraction osteogenesis of the edentulous atrophic maxilla. BMC Oral Health 2014; 14:116. doi:10.1186/1472-6831-14-116.

15. Pousette Lundgren G, Hasselblad T, Johansson AS, Johansson A, Dahllöf G. Experiences of being a parent to a child with amelogenesis imperfecta. Dent J (Basel) 2019;7(1):17. doi:10.3390/dj7010017.

16. Ghanei M, Arnrup K, Robertson A. Procedural pain in routine dental care for children: a part of the Swedish BITA study. Eur Arch Paediatr Dent 2018;19(5):365-72. doi: 10.1007/s40368018-0368-2.

17. Persson M, Sundell S. Facial morphology and open bite deformity in amelogenesis imperfecta. A roentgenocephalometric study. Acta Odontol Scand
1982;40(3):135-44. doi: 10.3109/00016358209012722.

18. Cartwright AR, Kula K, Wright TJ. Craniofacial features associated with amelogenesis imperfecta. J Craniofac Genet Dev Biol 1999;19(3):148-156.

19. Ravassipour DB, Powell CM, Phillips CL, et al. Variation in dental and skeletal open bite malocclusion in humans with amelogenesis imperfecta. Arch Oral Biol 2005;50(7):611-23. doi: 10.1016/j.archoralbio.2004.12.003.

20. Pavlic A, Battelino T, Trebusak Podkrajsek K, Ovsenik M. Craniofacial characteristics and genotypes of amelogenesis imperfecta patients. Eur J Orthod 2011;33(3):325-31. doi: 10.1093/ejo/cjq089.

21. Naik M, Bansal S. Diagnosis, treatment planning, and full-mouth rehabilitation in a case of amelogenesis imperfecta. Contemp Clin Dent 2018;9(1):128-31. doi: 10.4103/ccd.ccd_787_17.

22. Ng FK, Messer LB. Dental management of amelogenesis imperfecta patients: a primer on genotype-phenotype correlations. Pediatr Dent 2009;31(1):20-30.

23. Krieger O, Matuliene G, Hüsler J, Salvi GE, Pjetursson B, Brägger U. Failures and complications in patients with birth defects restored with fixed dental prostheses and single crowns on teeth and/or implants. Clin Oral Implants Res 2009;20(8):809-16. doi: 10.1111/j.1600-0501.2009.01720. x. 